\title{
Willingness of the Farmers' Participation in the New grain supply chains -based on the Technical Acceptance model*
}

\author{
Zhipeng $\mathrm{Gu}^{1, \mathrm{a}}$ and Baoming $\mathrm{Cao}^{2, \mathrm{~b}}$ \\ ${ }^{1}$ No.3 Wenyuan Road, Nanjing City, Jiangsu Province, China \\ ${ }^{2}$ No.128, North Railway Street, Gulou District, Nanjing City, Jiangsu Province, China \\ alikaiyounidejie@126.com, ${ }^{\mathrm{b}}$ 2000cbm@163.com
}

Keywords: Technology acceptance approach, Farmer, New grain supply chains, Willingness of participation.

\begin{abstract}
A new grain supply chains acceptance model is put forward. Based on the data of 378 rural households in Jiangsu Province, the empirical study shows that the intention of farmers' participation comply with the law of behavior psychology, which is affected positively by perceived usefulness and ease; getting higher income, higher product quality and more Efficient sales channel could improve the perceived usefulness for farmers. Otherwise, farmers demand more details for new grain supply chain, which has positive affect to perceived ease.
\end{abstract}

\section{Introduction}

With the formation of grain buy-side market, the conventional grain production and circulation mode can't satisfy the requirement of economic development adequately. Current competition of grain industry is not just a competition of "Single Substance", but a comprehensive competition which includes the entire industry chain and operation as system. And some new grain supply chains(NGSCs) modes have emerged in practice, such as "farmers-supermarket", "farmers-cooperative community", "firm-farmers", "farmers- manufacture corporate-supermarket" and etc. Compared with the traditional grain supply chain, "from field to table" is the key feature of new grain supply chains (NGSCs). Zhang Wen\& Li Lu Tang[1], Ji Liang Gang, et al.[2] conduct study on real cases about NGSCs with qualitative or quantitative analysis, on successful experience of specific case, obstruction factors in practice, strategy analysis and etc. However, it is not satisfactory since many places following the successful cases and without considering their own characteristics. Generally speaking, most of the farmers cannot benefit from the NGSCs due to their nature weak status in the entire grain supply chain, and due to the lack of ability to negotiate with supply and other relevant, the worst situation is that the farmers may be "captured" by other objects of grain supply chain, thus, some farmers may be reluctant to participate in the NGSCs. Leng Zhi Jie\& Zhao Pan Ying[3].Deng Jun Rong\& Qi Chun Jie[4] find that this will lead to the break of grain supply chain due to the failure of resisting external damage and may damage the stakeholders of the entire grain supply chain. Since scholars have realized the importance of farmers during the entire supply chain, many literatures were focused on the willingness of farmers participating the relevant supply model. However, the results of those scholars are different from each other and even some conflicts, such as Roy, D.\& Thorat A.[5], Chen Yu Sheng. , et al.[6], Zapata, C., et al.[7], Michelson, H., et al.[8].

Few literatures analyzed farmers' decision-making progress based on psychology. According to the behavioral psychology, the willingness of farmers to accept the NGSCs is not only determined by the subjective features of farmers such as gender, operation scale, agriculture income and etc.,

\footnotetext{
${ }^{*}$ This article is the stage results of National Natural Science Foundation of China (No: 71373116), Special Subject of Doctoral Candidates in Nanjing University of Finance and Economics (BSZX15-02), Jiangsu University Collaborative Innovation Center ( Jiangsu University Collaborative Innovation Center (Modern Food Circulation and Safety Collaborative Innovation Center) .
} 
but also affected by the objective principles and perceived behavior control. Thus, it is quite a complex psychological judgmental progress. Therefore, the willingness of farmers participating in NGSCs cannot simply explained by the farmers' households, society, economic features, but need to take the farmers' decision making psychological progress into account as well. This article is based on the acceptance theory of information technology, and aims to build the farmers' participation NGSCs model to analyze the key factors of explaining farmers' participation on NGSCs, as well as the mutual influence among these factors.

\section{Research hypothesis and conceptual model}

From 1970s, researchers have studied the intention and behaviour of both individual and groups using social psychology and organizational behavior theories. Technology acceptance model (TAM) is one of the most wildly-used models in information science. Lu Yaobin and Xu Hongmei[9] analyzes rational behavior theory, planned behavior theory and technology acceptance model comprehensively and then compares the main factor in each of them. Chen Yu and Yang Baojian[10] summarizes the technology acceptance model and extending, found that the choice and acceptance of information is determined by behavioral intentions, while the later is determined by the attitude of want-to-use and its perceived usefulness. Farmers use the object they perceived and the knowledge they obtained to make judgment. Then they implement the right choice which would lead to maximum benefit. In the process of making judgment, farmers not only have all kinds of psychological behavior, but also reveal different personalities. Using technology acceptance model, decision process of farmers can be explained as: first perceiving the characteristic factors in each node of NGSCs, second processing the information obtained and judging its usefulness and ease, third making choices and implementing actions.

\subsection{Variables selection}

NGSCs build on the symbiotic relationship between different partners. Farmers, agriculture-related firms and customers constitute a functional net-chain structure. Members of the structure cooperate tightly and share information together to reduce the cost of logistics and trade, and in order to respond quickly to market, enhancing the competitive power and increasing the value of the whole supply chain. Here is the definition of NGSCs perception usefulness and ease: perception usefulness is used to characterize the subjective measurement of efficiency improvement NGSCs brought after participating; perception ease is used to measure the level of effort have to take after participating NGSCs. Such as increasing farmers' earnings, ensuring food quality and guaranteeing food sales. The perception ease of NGSCs should be reflected in how to solve the dilemma brought by these problems. So it is useful to use three variables to measure the perception usefulness of NGSCs: farmers' income, food safety, food sales. The perception ease of NGSCs should be reflected on how to make farmers easy to understand and execute other demands NGSCs requested. Since there is great variety of specific patterns of NGSCs in the real world, each pattern has its own characteristic. This paper chooses three variables to measure the ease of perception: convenience of availability, simplicity of participation, easiness of understanding. When NGSCs is providing potential opportunities for farmers, it also asks the participating farmers to make some changes. So this paper focuses on the characteristic elements of NGSCs farmers and then uses three variables (variety of food plantation, input of labour and capital and the changing willingness of production form) to measure the participation willingness of farmers.

This paper uses Lukert's five-measuring scale to design the questionnaire and then assign the variables according to its intensity (1 is the lowest and 5 is the highest). Table 1 presents the specific definition of each variable. 
Table 1 Definition of variables

\begin{tabular}{|c|c|c|c|}
\hline class & Affecting factors & variable & Variable explanation \\
\hline \multirow{3}{*}{$\begin{array}{l}\text { Perception } \\
\text { of } \\
\text { usefulness } \\
\text { F1 }\end{array}$} & $\begin{array}{l}\text { Perception of income } \\
\text { fairness }\end{array}$ & PI & Whether to obtain fair income \\
\hline & $\begin{array}{l}\text { Perception of product } \\
\text { quality }\end{array}$ & PQ & Whether to increase grain quality \\
\hline & $\begin{array}{l}\text { Perception of easy } \\
\text { sales }\end{array}$ & PS & Whether to facilitate grain sales \\
\hline \multirow{3}{*}{$\begin{array}{c}\text { Perception } \\
\text { of ease } \\
\text { F2 }\end{array}$} & Access convenience & PG & $\begin{array}{l}\text { Whether to access service } \\
\text { conveniently }\end{array}$ \\
\hline & $\begin{array}{l}\text { Participation } \\
\text { convenience }\end{array}$ & PC & $\begin{array}{l}\text { Whether to facilitate farmers to take } \\
\text { part into NGSCs }\end{array}$ \\
\hline & Understanding easiness & PU & $\begin{array}{l}\text { Whether to help farmers understand } \\
\text { NGSCs }\end{array}$ \\
\hline \multirow{3}{*}{$\begin{array}{l}\text { Willingness } \\
\text { of } \\
\text { participation } \\
\text { F3 }\end{array}$} & Adjust grain plantation & WK & $\begin{array}{l}\text { Whether to adjust grain planation } \\
\text { according to NGSCs' request }\end{array}$ \\
\hline & $\begin{array}{l}\text { Adjust labor and } \\
\text { capital input }\end{array}$ & WI & $\begin{array}{l}\text { Whether to adjust labor and capital } \\
\text { input according to NASC's request }\end{array}$ \\
\hline & Adjust production form & WL & $\begin{array}{l}\text { Whether to adjust production form } \\
\text { according to NASC's request }\end{array}$ \\
\hline
\end{tabular}

\subsection{Research hypothesis}

We find that farmers won't understand and make judgment on the characteristic factors until they can master it. If the characteristic elements that NGSCs presents are hard to understand, farmers would be fear about it so as to reject NGSCs. In the meanwhile, the perception usefulness of NGSCs characteristic element in farmers' perspective would have effect on their willingness to take part into NGSCs. Farmers would tend to participate in NGSCs only if they think that its characteristic element is useful to them and it is beneficiary for increasing farm production and profit. So, here are the hypothesis aiming at its basic relationship.

H1: farmers' perception ease towards NGSCs would positively affect perception usefulness.

H2: farmers' perception ease towards NGSCs would positively affect farmers' participation willingness.

H3: farmers' perception usefulness towards NGSCs would positively affect farmers' participation willingness.

When farmers are deciding whether to take part into NGSCs, they would analyse and judge in different aspects the usefulness of NGSCs characteristic element in farmers' part. If the perception usefulness of NGSCs characteristic element in farmers' part is high and the expected return is large, farmers would choose to participate into NGSCs. If not, the farmers would not participation into NGSCs. Based on this point, this paper postulates hypothesis on the impact factors of perception usefulness of NGSCs characteristic element in farmers' part.

H4: perception of agriculture income would positively affect farmers' NGSCs perception usefulness.

H5: perception of grain quality and safety would positively affect farmers' NGSCs perception usefulness.

H6: perception of grain sales swiftly would positively affect farmers' NGSCs perception usefulness.

In deciding whether to participate into NGSCs, farmers would evaluate the ease of NGSCs characteristic element in farmers' part. They would tend to take part in NGSCs which is easy to obtain and understand. So we postulate hypothesis:

H7: The ease of understanding by farmers would positively affect farmers' perception ease.

H8: The ease of participating would positively affect farmers’ perception ease. 
H9: The ease of obtaining service would positively affect farmers' perception ease.

The willingness of farmers' participation into NGSCs is the result of famers' choosing behaviour of characteristic elements in farmers' part. Farmer' willingness is mainly reflected on the recognition of characteristic element. It then appears as changing and improving the individual production and operation behaviour according to characteristic element. In NGSCs, farmers' adjusting grain variety, labour and capital input and production form according to characteristic elements would have impact on their willingness of participating into NGSCs. So, we have the following hypothesis:

H10: farmers' adjusting grain variety would positively affect their willingness of participating into NGSCs.

H11: farmers' adjusting labor and capital input would positively affect their willingness of participating into NGSCs.

H12: farmers' adjusting production form would positively affect their willingness of participating into NGSCs.

\subsection{Conceptual model}

Based on the pervious research hypothesis, this article uses perception ease and usefulness as intermediary variables and uses farmers' willingness of participating NGSCs as resulting variable. Then we implement AMOS 22.0.0 to construct our structural function model. Figure 1 presents the structural function model. Judging through the causal relationship across the whole model, farmers' willingness of participating NGSCs is determined by the perception ease and usefulness. The perception ease has an indirect impact on the willingness by affecting perception usefulness first.

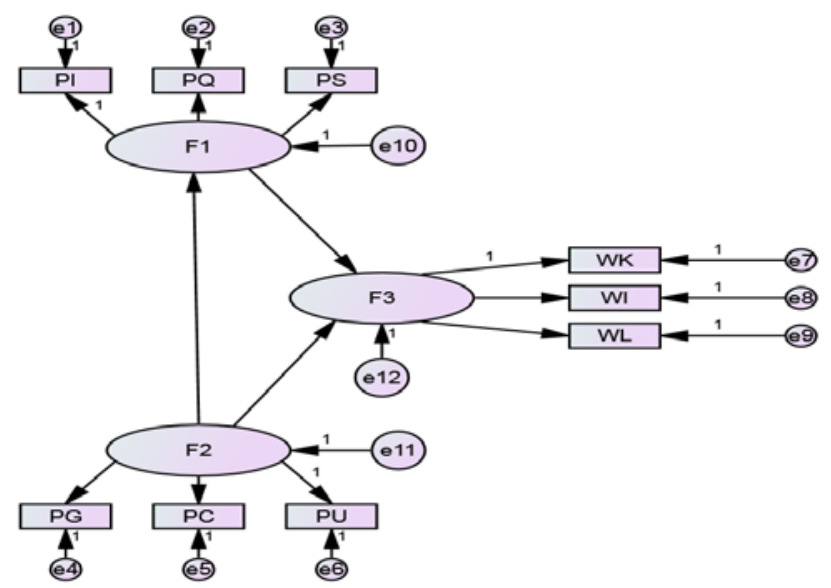

Fig.1. NGSCs acceptance conceptual model

\section{Questionnaire survey and data process}

\subsection{Investigation method}

At first We conduct a preliminary analysis and adjustment of the design questionnaire based on a small range of pre-research. Then we score each factor with the Likert scaling method. On the basis of questionnaire survey, 30 farmers are randomly selected from 378 samples by telephone interview and effective to $100 \%$. The objects of this investigation are selected from Jiangsu province, whose main agriculture income come from grain-grow. During this investigation 400 questionnaires are collected and $94.5 \%$ of the questionnaires are effective. According to Bentler and Chou (1987), sometimes the number of samples will be less than 200 in behavior and social science research, therefore, it is sufficient that each observation variable has 10 samples, While in this article, we have 9 observation variables and 378 survey data, it is sufficient to applied structural equation model.

\subsection{Questionnaire credibility and efficiency test}

To make sure of questionnaire's quality, we need to evaluate the appropriateness of question 
setting by testing its credibility and efficiency. This article adopts Cronbach's Alpha to conduct credibility test and then calculates the Cronbach's Alpha of the whole measuring scale and every single measuring scale (see table 2). Table 2 shows that all data of Cronbach's Alpha are larger than 0.6 , indicating that the credibility of this measuring scale is fine. Also, Alpha would be low if any one of the item is deleted. This makes sure that all items should be kept. The correlation between unit and total further shows that the correlation between each item and its reflecting project is larger than 0.6 , which is far more than 0.3 - a standard promoted by relevant researchers. So, we conclude that the structural efficiency of this questionnaire is fine.

Table 2 CITC\& Cronbach's atest score

\begin{tabular}{|c|c|c|c|c|c|c|c|}
\hline \multirow[b]{2}{*}{ Term } & \multirow[b]{2}{*}{ Item } & \multirow{2}{*}{$\begin{array}{l}\text { Avera } \\
\text { ge }\end{array}$} & \multirow[b]{2}{*}{ Std } & \multirow[b]{2}{*}{ CITC } & \multirow{2}{*}{$\begin{array}{l}\text { Cronbach's } \alpha \text { if } \\
\text { Item Deleted }\end{array}$} & \multicolumn{2}{|c|}{ Cronbach's $\alpha$} \\
\hline & & & & & & Single sale & $\begin{array}{l}\text { Whole } \\
\text { scale }\end{array}$ \\
\hline \multirow{3}{*}{$\begin{array}{l}\text { Perception } \\
\text { usefulness }\end{array}$} & PI & 3.673 & 1.099 & 0.724 & 0.814 & \multirow{3}{*}{0.859} & \multirow{9}{*}{0.869} \\
\hline & PQ & 3.805 & 0.984 & 0.711 & 0.825 & & \\
\hline & PS & 3.660 & 1.042 & 0.772 & 0.766 & & \\
\hline \multirow{3}{*}{$\begin{array}{l}\text { Perception } \\
\text { ease }\end{array}$} & PG & 3.717 & 0.695 & 0.686 & 0.739 & \multirow{3}{*}{0.819} & \\
\hline & PC & 4.107 & 0.690 & 0.610 & 0.811 & & \\
\hline & $\mathrm{PU}$ & 3.556 & 0.784 & 0.732 & 0.689 & & \\
\hline Participatio & WK & 3.447 & 0.662 & 0.694 & 0.718 & \multirow{3}{*}{0.812} & \\
\hline $\mathrm{n}$ & WI & 3.403 & 0.812 & 0.686 & 0.726 & & \\
\hline willingness & WL & 3.440 & 0.699 & 0.625 & 0.780 & & \\
\hline
\end{tabular}

This article uses factor analysis method. First, we conduct KMO test and Bartlett's sphere test to make sure whether it is appropriate to use factor analysis. The KMO test result is 0.822 and the Bartlett's sphere chi-square is 686.938 with $\mathrm{df}$ equals 36 . The p-value is 0.000 , indicating that it is appropriate to use factor analysis. Second, we conduct factor analysis. The three factors we extracted account for $76.27 \%$ of cumulative variance. Table 3 shows the overloading of each item in its own factors. We can see that each item fully reflects the predefined hypothesis and is universally larger than 0.7. Furthermore, no item has overloading larger than 0.4 in two or more factors. So there is no cross-overloading in bunch of items. This can be concluded that the questionnaire has good converging efficiency and distinguishing efficiency.

Table 3 Result of exploratory factor analysis

\begin{tabular}{cccc}
\hline \multirow{2}{*}{ item } & \multicolumn{3}{c}{ Component } \\
\cline { 2 - 4 } & 1 & 2 & 3 \\
\hline PQ & .852 & .040 & .208 \\
PS & .867 & .034 & .060 \\
PI & .901 & .006 & .061 \\
PC & -.100 & .811 & .193 \\
PU & .073 & .817 & .241 \\
PG & .111 & .836 & .276 \\
WL & .200 & .371 & .743 \\
WI & .377 & .373 & .689 \\
WK & -.018 & .189 & .882 \\
\hline
\end{tabular}

\section{Model Estimation}

\subsection{Model fitness evaluation}

In order to test the theoretical model this paper postulates, we use AMOS 22.0.0 to estimate the model first. Table 4 shows the fitting index of model. According to the simulation result, the chi-square of this model is 39.5. But the chi-square is 0 when the model fully fits the data. So the model does not show a distinct effect. However, the ratio of chi-square to degree of freedom is 1.646, which is close to $2-$ a standard Mueller [11] proposes. This rate shows that the fitness of the 
model is good. Also, the average square root of residual is 0.041 , which is close to 0 indicating the good fitness of the model. The approximated square root of error is 0.064 , which is lower than 0.08 - a standard proposed by Browne et al. [12]. The goodness of fit is 0.944 , indicating that the model fits data well. All the value-added fitness index is larger than 0.9, which meets the standard proposed by Bentler et al. [13]. The parsimony index of condensed fitness index reflects the number of estimated variables. Combining with the value of condensed fitness index which is larger than 0.5 - proposed by Byrne et al. [14], we conclude that the fitness of theoretical model this paper postulates is good.

Table 4 Fitness index of theoretical model

\begin{tabular}{|c|c|c|}
\hline & Fitness index & Value \\
\hline \multirow{6}{*}{ Absolute fitness index } & $\chi^{2}(\mathrm{CMIN})$ & 39.500 \\
\hline & \multirow[t]{2}{*}{$\begin{array}{c}\text { Chi-square } \\
\text { of fitness }\end{array}$} & 24 \\
\hline & & 1.646 \\
\hline & \multirow{2}{*}{$\begin{array}{l}\text { Average square root of } \\
\text { residual } \\
\text { Approximated square root } \\
\text { of residual }\end{array}$} & 0.041 \\
\hline & & 0.064 \\
\hline & Goodness of fit index & 0.944 \\
\hline & Standard fitness index & 0.954 \\
\hline & Broken fitness index & 0.913 \\
\hline Value-added fitness index & Comparative fitness index & 0.925 \\
\hline & Value-added fitness index & 0.966 \\
\hline & Relative fitness index & 0.930 \\
\hline \multirow[b]{2}{*}{ Condensed fitness index } & Parsimony index & 0.767 \\
\hline & $\begin{array}{l}\text { Condensed benchmark } \\
\text { fitness index }\end{array}$ & 0.602 \\
\hline
\end{tabular}

\subsection{Model estimation results}

Table 5 shows the estimation results of the model proposed by this paper. It can be shown that regression weights of variables are significant (p-value less than 0.05). So all the hypothesis this paper builds are supported by the data.

Table 5 Model estimation results and hypothesis tests

\begin{tabular}{|c|c|c|c|c|}
\hline \multirow[b]{2}{*}{$\begin{array}{l}\text { Endogenous } \\
\text { variables }\end{array}$} & \multicolumn{3}{|c|}{ Endogenous latent variables } & \multirow[b]{2}{*}{$\begin{array}{l}\text { Hypothesis } \\
\text { verification }\end{array}$} \\
\hline & $\begin{array}{l}\text { Perception } \\
\text { usefulness (F1) }\end{array}$ & $\begin{array}{l}\text { Perception } \\
\text { ease (F2) }\end{array}$ & $\begin{array}{l}\text { Participation } \\
\text { willingness (F3) }\end{array}$ & \\
\hline F1 & & & $0.266(5.056)^{* * *}$ & H1 confirmed \\
\hline F2 & $0.258(1.989)^{* *}$ & & $0.476(6.81)^{* * *}$ & H2 confirmed \\
\hline F3 & & & & H3 confirmed \\
\hline PI & 1 & & & H4 confirmed \\
\hline$P Q$ & $0.796(8.591)^{* * *}$ & & & H5 confirmed \\
\hline PS & $0.932(9.436)^{* * *}$ & & & H6 confirmed \\
\hline PU & & 1 & & H7 confirmed \\
\hline PC & & $\begin{array}{c}0.714 \\
(8.852)^{* * *}\end{array}$ & & H8 confirmed \\
\hline PG & & $\begin{array}{c}0.845 \\
(10.363)^{* * * *}\end{array}$ & & H9 confirmed \\
\hline WK & & & 1 & H10 confirmed \\
\hline WI & & & $1.35(10.244)^{* * *}$ & H11 confirmed \\
\hline WL & & & $0.901(8.511)^{* * *}$ & H12 confirmed \\
\hline
\end{tabular}


Note: Values in the parenthesis is the t-test score. $* * *$ indicates the variable is significant in $1 \%$ level. ${ }^{* *}$ indicates the variable is significant in $5 \%$ level.

\section{Research conclusion}

This article builds a new grain supply chains acceptance model from the perspective of farmer based on technology acceptance model. Empirical results show that all hypothesis are satisfied. This indicates that technology acceptance model has its power of efficiency in explaining the acceptance of new things. This article also concludes that farmers' subjective perception of new grain supply chains cannot be ignored in the process of promoting it new thing. The main result of our model estimation is as follows:

(1) It can be shown that the perception usefulness and ease have positive impact on farmers' willingness. If farmers have proper understanding of NGSCs and adequate knowledge about the demand of NGSCs, they would have better perception usefulness and ease towards NGSCs. So they would have more willingness to take part in this new system.

(2) Farmers' perception ease have positive impact on their perception usefulness. Farmers' perception usefulness is reflected by their own characteristics, such as participation, service acquisition and understanding of NGSCs. NGSCs which is easy to participation into will increase farmers' perception usefulness.

(3) From the perspective of impacting factors of farmers' perception usefulness, farmers' perception of income fairness, product quality and good sales has positive influence on the perception usefulness of NGSCs. This indicates that the perception usefulness would be elevated by increasing farmers' income, enhancing food quality and keeping marketing channels flowing through participating into NGSCs.

(4) The easiness of obtaining service in the process of agriculture production and management has positive influence on farmers' perception ease. This means that the NGSCs service should focus on expanding the variety of agriculture operation service, improving service quality and facilitating the convenience of getting service. The participating convenience of NGSCs has positive effect on farmers' perception ease. This indicates that farmers would fear and tend to maintain old operating habits when they encounter complicated rules of NGSCs. The ease of understanding has a larger positive impact on their perception ease of NGSCs, which further indicates that farmers have relative high demands on the details of the pattern of NGSCs.

\section{References}

[1] Zhang Wen, Li Lu Tang. The international experience of jointing farmers \& supermarkets and Its enlightenment to the development of Chinese agriculture market[J]. World Agriculture, 2013 (06):7-9+39.

[2] Ji Liang Gang, et.al.. The Dilemma and Breakthrough of Agricultural Product Supply Chain Integration[J]. Journal of Beijing Technology and Business University(Social Sciences), 2015(1):16-22.

[3] Leng Zhi Jie, Zhao Pan Ying. The integration of small farmers into the effective grain supply chain and the principle of integrated collaboration[J]. Logistics Technology, 2008(08):144-147.

[4] Deng Jun Rong, Qi Chun Jie. A Comparative Analysis of Farmers' Professional Cooperatives and Members' Orders' Performance - Based on the Investigation of Two Citrus Cooperatives in Hubei Province[J]. Rural Economy, 2012(12):121-124.

[5] Roy, D. , Thorat A. .Success in high value horticultural export markets for the small farmers: The case of Mahagrapes in India[J]. World Development , 2008, 36(10):1874-1890.

[6] Chen Yu Sheng. ,et.al.. An Empirical Analysis on the Factors Affecting Farmers' Organic 
Vegetable Production Desire - Taking Beijing as an Example[J]. Chinese Rural Economy, 2009(07):20-30.

[7] Zapata, C.,et.al.. Productive Inclusion of Smallholder Farmers in Brazil? s Biodiesel Value Chain: Program Design, Institutional Incentives and Stakeholder Constraints. Working Papers,2010.

[8] Michelson, H., et.al.. Small Farmers and Big Retail: trade-offs of supplying supermarkets in Nicaragua." World Development, 2012, 40(2): 342-354.

[9] Lu Yao Wu, Xu Hong Mei. A Comparative Study of Technology acceptance model and Its Related Theory[J]. Science \& Technology Progress and Policy, 2005(10):176-178.

[10] Chen Yu, Yang Bao Jian. A Comparative Study of Technology acceptance model and Its Related Theory[J]. Science \& Technology Progress and Policy, 2009(06):168-170.

[11] Mueller,R.O. Structural equation modeling: Back to basics[J].Structiral Equation Modeling, 1997(4):353-369.

[12] Browne, M.W., Cudeck, R.. Alternative ways of assessing model fit. In K. A. Bollen, L. S. Long (eds.), Testing structural equation models [M].Newbury Park, CA: Sage,1993:136-162.

[13] Bentler, P.M., Chou, C.P. Practical issues in structural modeling. Sociological Methods and Research,1987(16):78-117.

[14] Byne, B. M. .Structural equation modeling with Amos: basic concepts, applications and Programming[R].New Jersey: Lawrence Erlbaum Associates.2001. 